\title{
'No One Should Be Terrified Like I Was!' Exploring Drivers and Impacts of Child Marriage in Protracted Crises Among Palestinian and Syrian Refugees
}

\author{
Bassam Abu Hamad ${ }^{1}$. Samah Elamassie ${ }^{2}$. Erin Oakley ${ }^{3} \cdot$ Sarah Alheiwidi $^{4}$ \\ Sarah Baird ${ }^{5}$
}

Accepted: 16 June 2021 / Published online: 26 July 2021

(c) The Author(s) 2021

\begin{abstract}
Exacerbated by 9 years of conflict and displacement, child marriage among Syrian refugees appears to be increasing, while in Gaza, the noticeable reduction in child brides over the past two decades has recently plateaued. This comparative study explores drivers and consequences of child marriage in protracted crises, drawing on mixed-methods research from Gaza and Jordan with married adolescent girls and their parents. Our findings suggest that conflict reignites pre-existing drivers of child marriage, especially conservative norms around family honour and clan intermarriage. Poverty is a strong driver of child marriage among Syrian refugees, while social protection programmes and educational opportunities for girls have played a protective role in Gaza. In both contexts, our findings underscore the multiple and intersecting negative effects of child marriage on girls' health and bodily integrity, and point to the urgency of tackling this harmful practice to ensure that no adolescent is left behind.
\end{abstract}

Keywords Adolescent girls · Child marriage $\cdot$ Refugee $\cdot$ Conflict · Poverty $\cdot$ Gaza Jordan

\section{Résumé}

Exacerbé par neuf années de conflit et de déplacement de populations, la pratique du mariage d'enfants semble être de plus en plus fréquente parmi les réfugié.es syrien·nes, tandis qu'à Gaza, la réduction notable du nombre d'enfants mariées au cours des deux dernières décennies a récemment atteint un plateau. Cette étude comparative explore les facteurs et les conséquences du mariage d'enfants dans les contextes de crises prolongées, en s'appuyant sur des études utilisant des méthodes mixtes, menées à Gaza et en Jordanie avec des adolescentes mariées et leurs parents. Nos résultats suggèrent que le conflit ravive les facteurs préexistants de la pratique du

Bassam Abu Hamad ghsrcb@gmail.com

Extended author information available on the last page of the article 
mariage d'enfants, en particulier les normes conservatrices relatives à l'honneur de la famille et les mariages entre clans. La pauvreté est un puissant facteur de mariage d'enfants parmi les réfugié.es syrien-nes, tandis que les programmes de protection sociale et les opportunités d'éducation pour les filles ont joué un rôle protecteur à Gaza. Dans les deux contextes, nos conclusions soulignent les effets négatifs multiples et croisés du mariage d'enfants sur la santé et l'intégrité corporelle des filles, et soulignent l'urgence de s'attaquer à cette pratique néfaste pour faire en sorte qu'aucun·e adolescent.e ne soit laissé.e pour compte.

\section{Introduction}

Child marriage - a formal or informal union between two children under 18 or one child under 18 and an adult—is 'a harmful practice that violates human rights' (United Nations, UN Human Rights Council 2015). Globally, the prevalence of child marriage among girls is around $21 \%$ (UNICEF 2018) while $4.5 \%$ of young men were first married before age 18. The Sustainable Development Goals (SDGs) aim to eliminate this harmful practice by 2030 . Girls who married as children are very likely to be 'left behind' as they lack the choices and opportunities to participate in and benefit from development progress (ibid.). Despite being prohibited by international law, child marriage continues to rob thousands of Gazan and Syrian refugee girls of their childhood (UNICEF 2018; Palestinian Central Bureau of Statistics, PCBS 2018).

This article explores the drivers and impacts of child marriage in protracted crisis contexts, based on the experiences of adolescent girls in the Gaza Strip and in the Syrian refugee community in Jordan. Following the Gender and Adolescence: Global Evidence (GAGE) programme's conceptual framework, we explore the structural and contextual drivers of child marriage and its consequences. In line with SDG target 5.3 (Eliminate all harmful practices, such as child, early and forced marriage and female genital mutilations), the article aims to inform discussions about strategies to end child marriage in conflict-affected settings. We focus on two GAGE capability domains: health, nutrition, and sexual and reproductive health (SRH); and bodily integrity, including freedom from violence (for more information about the GAGE conceptual framework and capability domains, please see the editorial introductory article of this special issue). We explore the vulnerabilities experienced by married girls, within and across humanitarian contexts in Gaza and Jordan, to understand the extent to which drivers and consequences are comparable or highlight country-specific patterns.

\section{Context}

\section{Gaza}

Most of Gaza's 2 million people (66\%) are refugees (see Table 1 for an overview of key demographic characteristics). A blockade of the Gaza Strip since 2006 continues 
Table 1 Key demographic characteristics of Gaza, Syria and Jordan

\begin{tabular}{|c|c|c|}
\hline Characteristic & Gaza & Syria (pre-crisis) \\
\hline Total fertility rate & 4 Children per woman & 3 Children per woman \\
\hline Adolescent fertility rate & 66 Per 1000 live births & 47 Per 1000 live births \\
\hline Adult literacy rate $(\%)$ & 96.4 & 84 \\
\hline Population structure & $22 \%$ of population are adolescents & $\begin{array}{l}33 \% \text { of population under } 15 \text { years old } \\
20 \% \text { of population aged } 15-24 \text { years }\end{array}$ \\
\hline Key challenges & $\begin{array}{l}\text { In Gaza: } \\
\text { - } 66 \% \text { of population are refugees } \\
\text { - More than } 50 \% \text { of households live } \\
\text { below Palestinian poverty line } \\
\text { - Approximately } 50 \% \text { of households } \\
\text { are food insecure }\end{array}$ & $\begin{array}{l}\text { In Jordan: } \\
\text { - } 85 \% \text { of refugees live in host com- } \\
\text { munities } \\
\text { - } 15 \% \text { of refugees live in refugee } \\
\text { camps and ITSs } \\
\text { - } 86 \% \text { of refugee households live } \\
\text { below the Jordanian poverty line } \\
\text { - Approximately } 72 \% \text { of individual } \\
\text { refugees are food insecure }\end{array}$ \\
\hline
\end{tabular}

Sources PCBS (2015), UNICEF (2014) and World Bank (2019)

to restrict movement of people, goods and services. Israeli de-development policies have depressed Gaza's economy (United Nations Population Fund, UNFPA 2016), with more than half of households now living below the poverty line and youth unemployment at more than 60\% (PCBS 2018). Adolescent girls face varied opportunities and restrictions as they progress towards adulthood despite high levels of education (over 95\% are literate) (PCBS 2019a). Many of the restrictions faced by girls are rooted in Arab culture, whereby 'family honour' is perceived as besmirched if women or girls engage in (or are even suspected of being engaged in) any sexual activity outside of marriage (Elakkary et al. 2014).

\section{Jordan}

Since the beginning of the Syrian crisis, an estimated 1.2 million Syrians, including 660,000 registered refugees, have fled to nearby Jordan - a country with a long history of hosting the region's refugees (United Nations High Commissioner for Refugees, UNHCR 2019). As Table 1 shows, approximately $86 \%$ of Syrian refugees in Jordan live below the poverty line. Most (85\%) live in host communities, while $15 \%$ live in formal refugee camps or informal tented settlements (ITSs) (World Bank 2019).

Isolation, discrimination and safety concerns, combined with poor-quality education, help explain why $20 \%$ of refugee children and $30 \%$ of adolescent refugees are not in school in Jordan (Abu-Hamad et al. 2019). More than half of caregivers (57\%) admitted that they restricted their daughters' mobility to keep them safe (ibid.). Girls and women face additional gender-related barriers, due to social norms and laws in Jordan that position them as second-class citizens. 


\section{Legal Context for Child Marriage}

In Gaza, Syria and Jordan, the legal framework for child marriage is complex and sometimes contradictory. In Gaza, for example, centuries of occupation have created a legal framework that comprises a patchwork of laws originating from several outdated legal systems. Until recently, the legal age of marriage was open to interpretation by the judicial system, which permitted girls over the age of 16 and a half in Gaza to marry (UNFPA 2016). Although marriage registration is mandatory in Gaza, failure to register a marriage does not invalidate it (ibid.). In Syria and Jordan, the legal age of marriage is clearly delineated; however, significant power still rests with judges, who can grant exceptions. Under the Syrian personal status law, the minimum legal age of marriage is 18 years for boys and 17 years for girls (Higher Population Council 2017). However, girls are able to marry at 13 years and boys at 15 years with judicial consent (ibid.). In Jordan, the legal age of marriage is 18 but judges can allow younger girls (previously as young as 15 , which increased to 16 in April 2019) to marry in exceptional cases (ibid.).

\section{Literature review}

\section{Magnitude of Child Marriage}

Worldwide, approximately 12 million girls are married each year before the age of 18 (UNICEF 2018). Their childhood is abruptly ended, and they face a life of poverty, deprivation and marginalisation. The International Center for Research on Women, ICRW (2016) reports that nearly $10 \%$ of girls in low- and middle-income countries (LMICs) are married before the age of 15, with girls from the poorest and least-educated families at greatest risk. Although child marriage is a crime under international law, the practice is widely socially accepted in many Arab countries, including Palestine, Jordan and Syria. The prevalence of child marriage among women currently aged 20-24 years in the Middle East and North Africa (MENA) region is estimated at $17 \%$ (ibid.).

Although there has been substantial progress over the past 25 years in reducing the prevalence of child marriage in the MENA region-dropping from one in three total marriages involving a child to just one in five-progress has slowed over the past decade. The region is not currently on track to meet the SDG target of eliminating this harmful practice by 2030 (UNICEF 2018). Stalled progress (or even reversal of gains) on child marriage in some countries may be attributable to conflicts in Iraq, Libya, Syria and Yemen. There is evidence that child marriage is becoming more common in some conflict-affected areas, especially Syria and Yemen, as families struggle to balance economic security and girls' safety in contexts where rape, abduction and forced 'marriage' are used as weapons of war (Women's Refugee Commission, WRC 2016). Before the Syrian crisis, data from 2006 to 2012 show that $13 \%$ of Syrian girls were married before the age of 18 and $2.2 \%$ married before 15 (UNICEF 2014), with variation across governorates. More recent findings from Syrian refugee communities suggest that the rate of child marriage may be 
four times higher than before the Syrian crisis. At the Girl Summit in July 2014, the Jordanian government signed a charter committing to end child marriage by 2020 (Higher Population Council 2017), but this has not been achieved.

Although Palestine has committed to eliminating child and forced marriage by 2030 , it is still widely practised, with at least $28 \%$ of married women (aged 15-45) wed as children (PCBS 2015), although this figure is down from $38 \%$ in 2010, and a 50\% decline compared to 2004. The most recent PCBS survey indicates that $17 \%$ of women aged 20-24 years married before age 18 (PCBS 2020). Palestinian governmental bodies and UN agencies have failed to agree on priorities and steps for addressing child marriage (UNFPA 2016). Palestine's personal status code is not only outdated, it is at odds with the government's new commitments to end child marriage (ibid.).

\section{Drivers of Child Marriage}

The literature suggests that many factors interact to place a child at risk of marriage, including poverty, fear of exposure to sexual violence, the need to protect family honour, and the desire for stability during a crisis (Presler-Marshall et al. 2020; Elarab and Sagbakken 2019; WRC 2016). Poverty is one of the main drivers of child marriage in the MENA region (Presler-Marshall et al. 2020), as parents consider daughters an economic burden and believe they will be more financially secure once their daughters are married off and no longer their responsibility. Child marriage tends to increase in emergency/conflict settings due to displacement, instability and poverty (ibid.). In conflict-affected contexts, weakened institutions and financial hardship leave adolescent girls vulnerable to abuse, exploitation and violence (WRC 2016). Poor families that lose jobs or land during a crisis can see child marriage as a way out of poverty.

Child marriage is also driven by social norms. Exacerbated by the ongoing conflict in the region, studies show that conservative social norms create additional stressors for girls, including child marriage (Presler-Marshall et al. 2020; Samuels et al. 2017). Religious affiliation, commitment and beliefs also influence norms and, subsequently, timing of marriage (UNFPA 2016); families with stronger religiosity are more likely to marry daughters earlier, especially as sex and childbearing outside of marriage are strictly proscribed by Arab culture. Other reported drivers of child marriage include girls' low educational attainment, a hostile school environment, gender inequality, limited voice and choice for girls, and a weak legal and policy framework (UNICEF 2018).

In Gaza, one study that included 600 female participants who had married as children identified customs and traditions (35\%), consanguinity (sharing ancestry) $(15 \%)$, having many sisters $(14 \%)$, poverty (18\%) and child brides' lack of understanding of the real meaning of marriage as major drivers of child marriage (Women's Affairs Centre, WAC 2014). Among parents of early-married girls, $14.4 \%$ indicated that the ongoing conflict drives child marriage because families want to protect their daughters from violence, insults and rape. Nearly a quarter of parents (22\%) reported that the upsurge of violence in 2014 made them more favourable to 
child marriage (ibid.). In Jordan, Syrian refugees married to Jordanian men are able to gain more social respect and prestige, and can legally move away from the refugee camp (Bukman 2018). This motivated some families living in refugee camps to wed their young daughters to Jordanian men.

\section{Consequences of Child Marriage}

Child marriage can have devastating effects: it cuts short a girl's education, compromises her bodily integrity (including her sexual health and reproductive rights), limits future employment and earnings, and perpetuates poverty (Tasker 2018; Bukman 2018). The literature shows that child brides are excluded from development priorities, particularly health, education, economic growth, and voice and agency (Elarab and Sagbakken 2019).

In the MENA region, new brides are expected to demonstrate their fertility soon after marriage by producing a male heir (UNFPA 2016). According to the World Health Organization, WHO (2014), 16 million adolescent girls give birth every year, and complications during pregnancy and childbirth are a major cause of death for girls aged 15-19 years. The prevalence of stillbirths and newborn deaths is 50\% higher among young mothers (below 20 years) (ibid.). Married girls are exposed to the risks of teen pregnancy, childbearing and motherhood before they are physically and psychologically ready (ibid.), so can experience prolonged/obstructed labour.

Even though some parents believe that marrying their daughter early will protect the girl from sexual violence, the reverse is often true. Girls who marry before the age of 18 are more likely to experience violence, especially when the spousal age gap is large (Clark et al. 2017; Al-Modallal 2012). Another study found that girls who were married before 18 were twice as likely to report domestic violence and also showed signs of severe depression (Gausman et al. 2020). In the Gaza Strip, $63 \%$ of early-married girls were exposed to at least one type of violence, compared with $51 \%$ of older women (PCBS 2019b).

Married girls are also exposed to violence in their community as they may become separated from their older husband or even become widowed (BraunLewensohn and Al-Sayed 2018). They are also frequently exposed to divorce when the marriage is informal ('Nikah Urfi' - a marriage conducted by a Muslim cleric in the presence of two witnesses, which is not officially registered). Girls who are married in this way can be abandoned or divorced, leaving them with little protection (Karasapan and Shah 2019).

\section{Methodology and Design}

This article draws on participatory mixed-methods research in Gaza and Jordan, as part of the GAGE 9-year longitudinal research programme. In Gaza, in 2016 and 2017, we conducted qualitative interviews with adolescents, their peers and families. This included 17 focus group discussions (FGDs) as well as 35 in-depth interviews (IDIs). We also undertook participatory research involving 35 adolescents benefiting 
from empowerment programmes, using a range of interactive tools to explore drivers of child marriage and associated gender norms. In early 2019, we complemented the qualitative work with a survey of 406 randomly selected female participants who had married as children.

In Jordan, we draw on the GAGE baseline survey with adolescents and their primary female caregivers, conducted in late 2018 and early 2019. We also draw on GAGE's accompanying baseline qualitative research, which involved interviews with 220 adolescents and 158 key informants, mainly staff at UNICEF's Makani centres (which provide a safe space for children and young people to access learning opportunities, child protection and other services), as well as 30 FGDs with caregivers.

\section{Target Population and Study Sites}

In Gaza, the target population was disadvantaged adolescents, including married adolescents, their peers and families, and service providers. We surveyed randomly selected mothers aged below 25 years but who had married before 18, from the Gaza Strip's five governorates, including refugees and non-refugees (406 selected out of a total population of 12,173). We obtained a list of eligible married girls from the National Civil Registry and, using the Epi Info calculator, selected a representative sample. The qualitative research used a purposive snowball sampling technique to ensure a good mix of participants from different socioeconomic backgrounds, including school dropouts, adolescent mothers, child brides, divorced/separated adolescents, and adolescents with disabilities. We interviewed 62 married children and their caregivers. The quantitative survey covered the entire Gaza Strip and was conducted through face-to-face household interviews while the qualitative research was conducted in three diverse localities (Jabalia camp, Shajaia and Khan Younis), with interviews conducted at the premises of community-based organisations.

In Jordan, our quantitative sample comprised 4101 adolescents, equally split by sex (girls and boys) and by age cohort (younger adolescents aged 10-12, and older adolescents aged 15-17). Because sampling was based on household vulnerability (see Jones et al. 2019), and refugee households are more vulnerable than Jordanian households, our sample has $85 \%$ refugees, including those living in host communities, camps and ITSs. In line with the SDGs' mandate to leave no one behind, we also deliberately oversampled some groups of particularly marginalised adolescents, including those with disabilities, girls who are (or have been) married and school dropouts. This sample included 158 Syrian refugee girls married before the age of 18. Our qualitative sample, comprising 240 adolescents, was purposively selected from the larger sample to explore adolescent experiences and perspectives in more depth. We interviewed 25 ever-married Syrian refugee adolescent girls. In Jordan, the quantitative and qualitative work was carried out in Amman, Mafraq, Irbid, Zarqa and Jerash - these are the five governorates where most Syrian refugees live. 


\section{Data Analysis}

Analysis of the quantitative data was conducted using Stata 14 and Stata 16 in Jordan and SPSS 25 in Gaza. For qualitative data, following transcription and translation, interview transcripts were thematically coded and analysed using a codebook that was informed by the GAGE conceptual framework (GAGE Consortium 2019). Coding was completed using MAXQDA 12 software by a team of four experienced coders who received tailored training.

\section{Research Ethics}

The research team adhered to stringent ethical measures to protect adolescents and their families as per the GAGE Institutional Ethics approval document and GAGE Child Protection guidelines. We also followed the Modified International Code of Ethics Principles (1975) known as the Declaration of Helsinki. Permission was sought, and given, from Gaza's Helsinki Committee (PHRC/HC/134/16) and we also sought approval from the Jordanian government (19/29/92789/224879). The GAGE research programme was also approved by the George Washington University Committee on Human Research, Institutional Review Board (071721), and the Overseas Development Institute Research Ethics Committee (02438). Participants' anonymity and confidentiality were assured and data were securely stored. Informed consent from parents and adolescents aged 18 and older, and informed assent from adolescents aged under 18 years, was obtained prior to commencing each data collection activity. Interviews took place privately in convenient and safe places with maximum privacy and confidentiality to allow free expression of thought. Official agreements on referral pathways for cases that needed urgent support were made with service providers.

\section{Key Findings}

\section{Profile of Child Brides in Gaza}

Among our sample of married Gazan girls, the mean and median age at first marriage was 16 years; $24.9 \%$ had married when they were $12-15$ years. In general, they married men who were much older than them: $57 \%$ of respondents reported that their husband was at least 6 years older, while $9 \%$ reported that their husband was 10 years older or more. More than half $(55.4 \%)$ of girls married as children reported marrying a relative- - higher than the figure (39\%) for the general population (Sirdah 2014).

Our study suggests that almost all child marriages in Gaza are forced; only 6.5\% of participants reported not being forced into marriage. Girls who married young are more likely to belong to large families (mean family size 9 members) and extended families. Families of child brides are not particularly poor; the median family income 
reported by married girls was around 1000 Israeli shekels (ILS) (or \$350) per month (mean 1310 ILS or \$458). The vast majority (80\%) described their premarital housing conditions as good, and $73.6 \%$ were receiving social assistance, which is similar to the figure for the general population (PCBS 2018). These patterns suggest that motivations to marry girls before adulthood in Gaza are social and cultural rather than economic. Nevertheless, parents of child brides have less education-only $2.7 \%$ of mothers and $10 \%$ of fathers had completed university education-reflecting lower educational attainment than among the general population (23\% among males and $23.6 \%$ among females over 15 years old completed university education) (ibid.). Of girls who married early, $18 \%$ were out of school at the time of their engagement.

\section{Profile of Syrian Child Brides in Jordan}

Among the 158 married Syrian girls identified in the Jordan baseline survey, the median age at marriage was very low (15 years), indicating that half had married at age 15 or younger. Syrian married girls belonged to large families (mean number of living siblings was 6.5), with many sisters (mean 3.3); $12 \%$ had lost one or both parents. Among currently married girls, the average family size was large (mean 6.86 household members). When asked about their household income, $49 \%$ of caregivers of married Syrian girls reported that their current status in Jordan was 'lower income', compared to just $8 \%$ who reported that they were 'lower income' while living in Syria before the crisis, indicating a dramatic deterioration due to displacement. Because of their vulnerability, $87 \%$ of married girls' households had ever received World Food Programme (WFP) food vouchers, with 32\% receiving cash transfers from UNICEF or UNHCR.

Among married Syrian girls, 65\% were living in host communities, $29 \%$ in camps and $6 \%$ in ITSs, although there was a higher prevalence of child marriage among Syrian girls in camps and ITSs compared to host communities. Similar to Gaza, the median age difference between spouses was 5 years (mean 5.9), with $40 \%$ of Syrian child brides wed to men who were 6-10 years older and $8 \%$ wed to men who were 11 years older or more. More than three-quarters (77\%) of child brides had known their spouses for less than a year before they married; $26 \%$ had known them for less than a month.

\section{Drivers of Child Marriage in Gaza}

In Gaza, survey respondents (married girls) mostly cited cultural rather than economic drivers of early marriage (Fig. 1), with $83 \%$ citing strict conservative family norms and $74 \%$ citing social norms, and 53\% citing religious beliefs as the driver of child marriage which is very much in line with the literature (WAC 2014; UNFPA 2016). These beliefs underpin gendered perceptions about women's roles (as caregiver and nurturer) and encourage early marriage and childbearing solely through the institution of marriage (Ouis 2009; Presler-Marshall et al. 2020). Consanguineous marriage remains common (53\%). A 16-year-old married girl from Shajaia stated, 'My cousin wanted me, and my dad agreed. I didn't want to marry early, but 


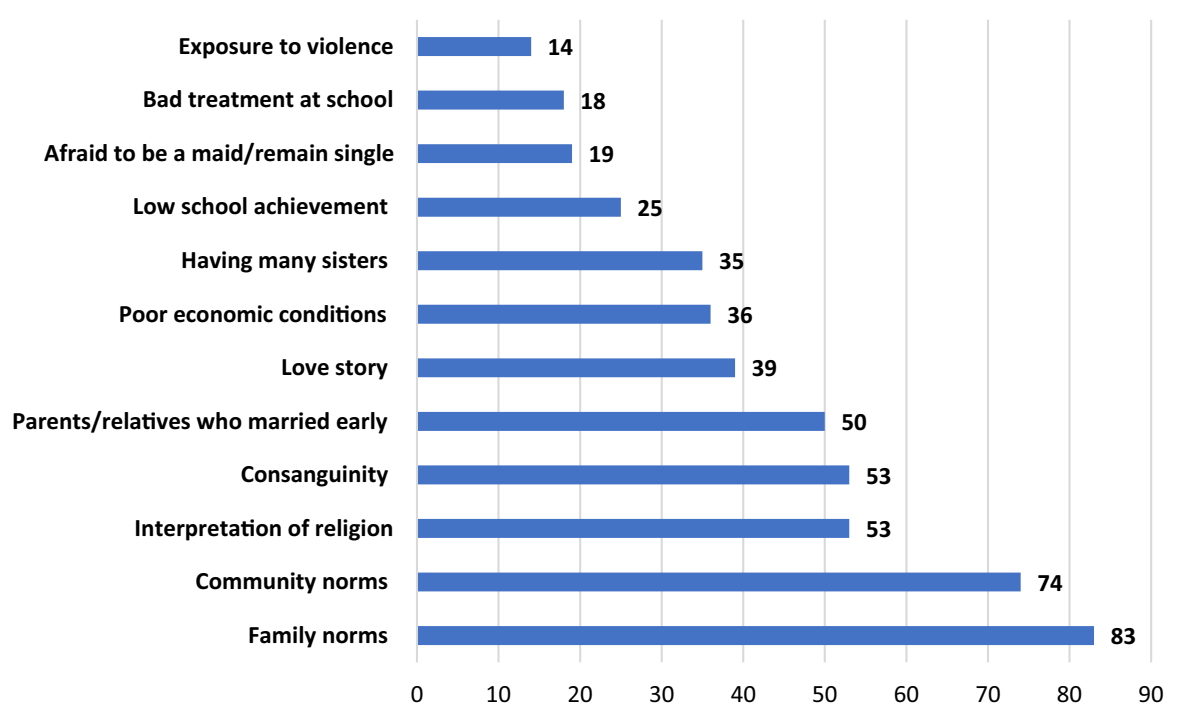

Fig. 1 Reported drivers of early marriage in Gaza $(n=406)$

also, didn't want to make problems in the family'. Similarly, a 17-year-old divorced girl from Jabalia camp said, 'My uncle approached my father and they decided that we marry as cousins, this is the norm in our culture'.

Other less commonly mentioned drivers of early marriage include falling in love (39\%), long-term economic hardship (36\%) and having many sisters (34.7\%). A 17-year-old girl from Khan Younis stated, 'I was married at age 14 to a man more than twice my age. 1 did not want to marry as a child. I wanted to attend university and become a journalist. However, because I am one of 13 children, including 8 sisters, my father decided against my wish in order to reduce expenses'. When asked about the drivers of child marriage, many adolescent participants in Khan Younis cited poverty and financial hardship.

Our qualitative work indicated that school dropout drives child marriage in Gaza; a quarter of the surveyed women who were married as children cited low school achievement as a driver of child marriage, while $18 \%$ identified bad treatment in school. One participant in an FGD with older girls in Jabalia explained: 'When I told my mother about boys who annoy me on my way to school, she got angry and prevented me going back to school. Then I got married directly after I dropped out [of] school'. Another out-of-school girl, in an IDI in Shajaia, confirmed: 'I had left in 9th grade, at age 15. I left when I got engaged'.

Other factors reported as driving child marriage include fear of losing the opportunity to marry after passing the age of 18 years (19\%), being an orphan (4\%), a rich groom $(4 \%)$, having a stepmother $(2.5 \%)$ or family need for the dowry $(1 \%)$. These reports echo the findings of other studies in Gaza (WAC 2014; UNFPA 2016). 


\section{Drivers of Child Marriage Among Syrian Refugees in Jordan}

Although our quantitative survey with Syrian refugees did not ask directly about drivers of child marriage, the profile of married girls (as discussed earlier) provides signals about what motivates families to marry their daughters early, including poverty, displacement, limited access to education, consanguinity and cultural norms. In line with the literature, our qualitative findings affirm that poverty plays a central role (Presler-Marshall et al. 2020; UNICEF 2018). The mother of a married Syrian adolescent girl said, 'Families want to marry their daughters quickly to be free of their burden' (IDI, refugee camp). The mother of a 15-year-old Syrian married girl said, 'We marry girls at a young age because of poverty only; there is no other reason'. Although most married girls in our qualitative research noted that they had not wanted to marry, a few reported genuine interest in marriage, sometimes because they thought it would improve their financial situation.

In the context of displacement and conflict, parents are fearful for girls' safety and their 'honour', so use marriage as a way to safeguard their daughters. The Syrian crisis has propagated kidnapping and trafficking by radical groups, with thousands of women and girls forced into sexual slavery (UN, 2019). Participants' responses indicate that child marriage was seen as a form of 'protection'. As one mother explained: 'Families want to marry their daughters quickly because they are worried about them. They worry about their exposure to violence'. Another Syrian mother from a host community noted, 'We marry the girls off at a young age because there is no safety'. Similarly, a Syrian refugee caregiver from a host community added, 'Here, life is difficult, and risky, people always feel humiliated'.

Even prior to the Syrian crisis, child marriage among Syrian families was driven by cultural and familial conservative gender norms. This may be related to the centrality of marriage for women in Arab culture and the preoccupation with family honour (UNFPA 2016). Respondents in our qualitative research reported that Syrian girls marry as young as 12 , when families may no longer see girls as children. 'We no [longer] consider girls at 9th grade as a young girl', explained a Syrian mother in a host community. Another married girl living in a host community said, 'One of my cousins got married when she was at the preparatory school because her family noticed that her body is suitable for marriage'. Findings from quantitative data in Jordan show that at least half of the mothers of currently married Syrian refugee girls in our sample had married as children themselves (80 of 115 caregivers who shared this information confirmed marrying at age 17 or younger)—suggesting that this type of early marriage may be common and expected among certain Syrian families. The mother of a 16-year-old married girl from a host community in Jordan explained, 'The situation in Syria is unlike Jordan... In Jordan, they marry girls after they finish their education... We follow the thoughts of Syrians; marriage is more important than education for girls'.

Syrian refugees affirmed the role of descriptive norms (what people believe others in the community do-for example, "most adolescent girls in my community marry before the legal age') and injunctive social norms (what people believe others in the community think ought to be done-for example, 'adults in my community expect adolescent girls to marry before the legal age') (see Fig. 2). Girls, and especially 


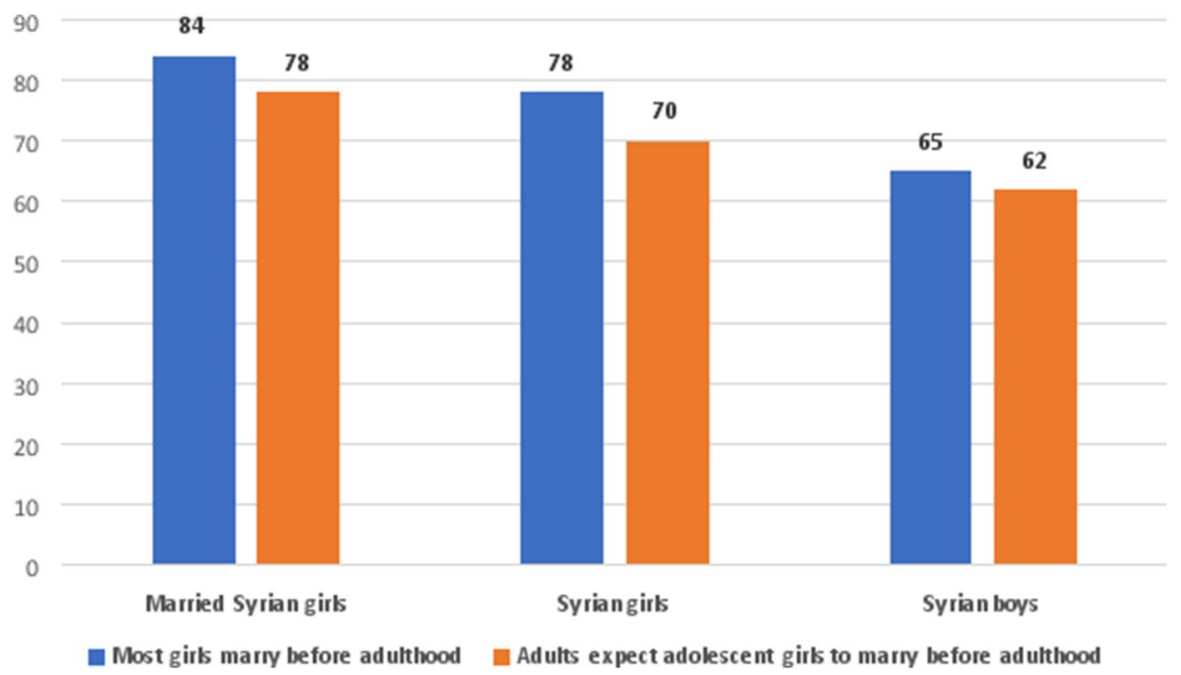

Fig. 2 Reported responses regarding descriptive and injunctive norms around child marriage $(n=158)$

married girls, were more likely to affirm child marriage norms than boys-presumably because they are more sensitive to them because they are the ones directly affected. Our findings also reveal that marriage is seen as a way to control girls and keep them from becoming too 'open minded' due to the 'influence of their friends' (mother in a host community). There is a tension here between upholding gendered norms and protecting girls from them. Several Syrian fathers, for example, explained that educating girls is largely pointless, because after marriage 'all her degrees will go away'. It is also seen as easier for the groom and his family to 'shape' younger girls according to their preference. The husband of a 15-year-old Syrian girl said, 'I raised her, I knew everything about her. It's like the doll, you can move it as you like... It's better than getting a mature girl who already has other things'.

Similar to Gaza and driven by cultural norms, consanguinity remains a strong motivator for early marriage among Syrian refugees (mainly between first cousins). The youngest brides are the most likely to marry a relative, as a 17-year-old living in Azraq camp (Jordan) explained: 'Our customs and traditions stipulate that priority in marriage is for the cousin'. An 18-year-old married Syrian girl noted, 'My uncle told [my father] that there would be hatred if we refused the marriage'. Particularly in the Arab context, the rate of consanguinity increases with low education, conflict and poverty, but also has future repercussions, as consanguineous marriages are more likely to produce children with disabilities (Sirdah 2014).

Our analysis also shows that school enrolment plays an important protective role against child marriage. The literature confirms that Syrian girls who drop out because of bullying, harassment, security concerns, lack of resources or parents' limited commitment to formal education (especially those living in ITSs) are more likely to marry as children (Abu-Hamad et al. 2019; Presler-Marshall et al. 2020). A mother from Zaatari camp added, ' ... her father married her, made her leave 8th grade... her first day of 16 years, because of the verbal harassment of her peers'. 
Other mothers see education as a way to help their daughters avoid child marriage and early motherhood. A 15-year-old girl living in Azraq reported, 'My mum was married twice, once at 14 and a second time at $18 \ldots$ and she encourages me not to get married young and to finish my education...'.

It could be argued that protracted conflict in both contexts undermines efforts to combat child marriage, but in highly context-specific ways: in Gaza, the conflict has slowed the reduction in child marriage, while among Syrian refugees, ongoing conflict has increased the practice. Although conflict increases the likelihood of child marriage - as documented both in the literature (Ouis 2009; Elarab and Sagbakken 2019) and in our empirical work in Jordan — other factors such as access to education and social support have contributed to a decrease in child marriage in Gaza.

\section{Consequences of Child Marriage}

Married girls in both contexts reported negative experiences, feeling regret, brokenness, suffocation and some even likened marriage to being kidnapped. Many described marriage as a 'jail', which 'ended their childhood', considering it as 'the end of life' (IDI, 18-year-old girl, Shajaia). Figure 3 shows the reported negative consequences of child marriage on girls' capabilities in Gaza.

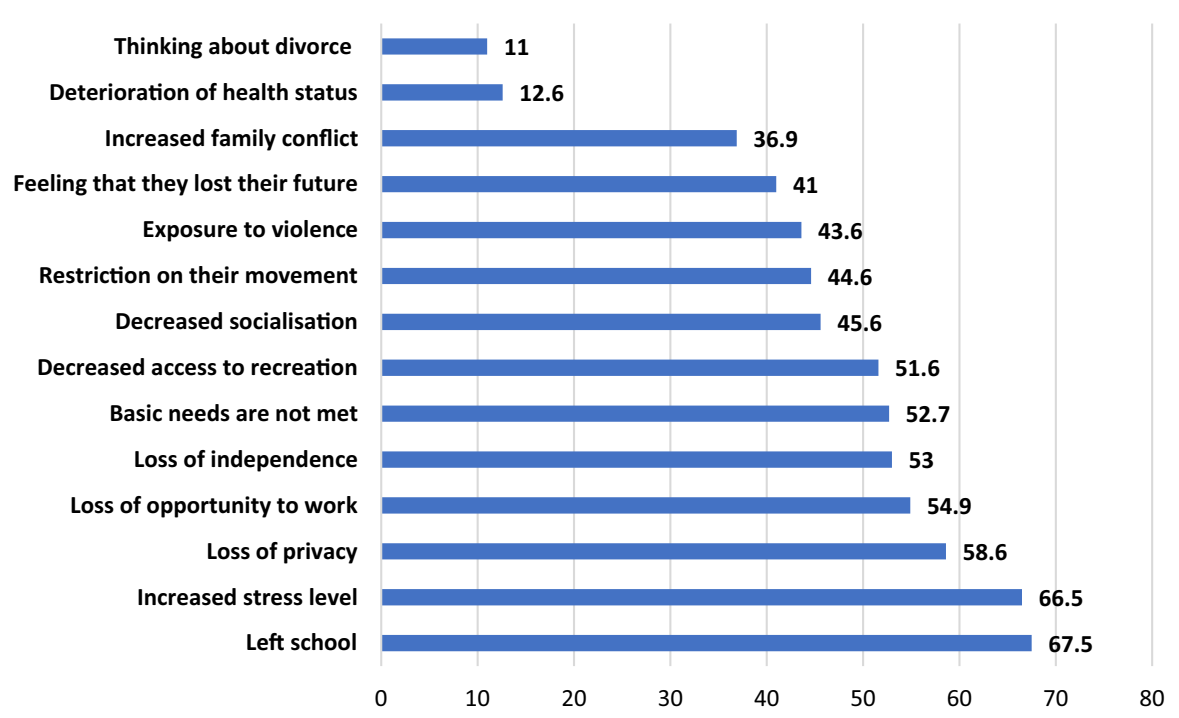

Fig. 3 Reported consequences of child marriage for girls in Gaza $(n=406)$ 


\section{Bodily Integrity and Freedom from Violence}

A considerable percentage of adolescents in Gaza (17.7\%) tried to escape domestic violence by getting married; however, their exposure to violence increased significantly after marriage, with $45 \%$ of girls reporting being exposed to violence from a wide range of perpetrators (Fig. 4). Most violence against child brides took place at home (95\%), and perpetrators were mainly spouses (94\%) and in-laws (21\%). Married young girls in Gaza are exposed to different kinds of violence, particularly verbal violence (93\%), physical violence (45.9\%), psychological violence $(37 \%)$ and economic violence (8\%). Married girls exposed to domestic violence largely internalised their suffering; $37 \%$ did not tell anyone about it, while many (48\%) returned to their parents. None reported accessing professional support. These findings resonate with other studies conducted in the region (PCBS 2019b; WAC 2014).

Household violence was also reported by married Syrian girls living in Jordan. Among the girls in our sample, more than a quarter $(27 \%)$ had experienced or witnessed violence in the past 12 months; of those girls, just $38 \%$ had spoken to someone about it. When asked about perceived personal safety, $20 \%$ of married girls (across locations) did not feel safe walking in the community during daytime, while $75 \%$ did not feel safe walking around at night. Only half of the married Syrian girls reported knowing where to seek services if they were exposed to violence.

Our qualitative work resonates with our quantitative findings, with married girls reporting being exposed to violence, particularly from husbands and in-laws. One married girl in Gaza said, 'Once my father-in-law hit me with an electric wire' (FGD, Jabalia). Many reported not being able to cope with family problems and violence, with some using violence against their children: 'I practise violence on my children because I am distressed!!' (14-year-old married girl, Khan Younis). Husbands abuse young married girls in several ways, ranging from controlling behaviour to physical and sexual violence. In Gaza, one married girl explained, 'Sometimes I would ask my husband for permission to go out, a week in advance and he accepts. However, when [the] time comes, he simply says no. When I ask him why, he does not have any good reason. He just likes to verbally abuse me' (FGD, older girls, Shajaia). In Jordan, one 19-year-old Syrian girl recounted: '[My husband] used to pour water in my ears, because these things don't leave any mark on the outside'. Another married girl—an 18-year-old living in an ITS—described mistreatment by her husband: 'He beats me with his hand, foot, or a stick'.

Fig. 4 Distribution of married girls in Gaza who reported exposure to violence $(n=406)$

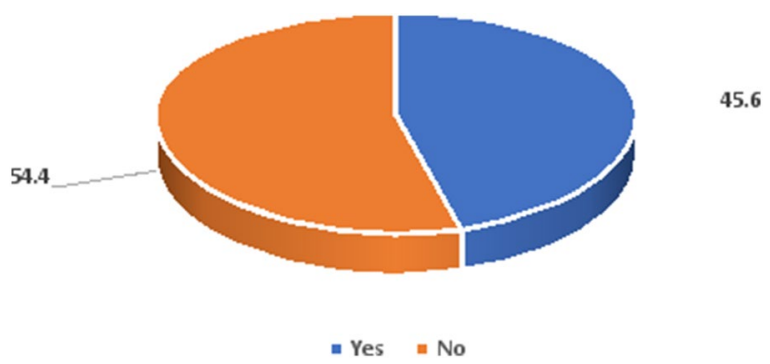


Sexual abuse by husbands was also commonly reported, particularly during the first sexual contact with their young bride. In Gaza, many participants described their first intercourse as 'scary' and 'strange', with one girl saying, 'I thought that marriage was all about supporting my husband. I had no idea that it included a sexual relationship'. One 15-year-old girl stated: 'My first day of marriage was the worst experience in my life, I had no idea what marriage was. The night of my wedding, I ran away from home. I went back to my family. I was terrified' (IDI, Shajaia). Syrian refugee girls who married as children reported a similar lack of knowledge surrounding sex and marriage before they wed; this topic is explored further in the subsection on 'sexual and reproductive health'.

Some married girls are also abused by other family members, including inlaws and their own family members. One 17-year-old Syrian girl living in Jordan explained: 'I lived with my mother-in-law. She would ask my brother to beat me'. Another 17-year-old Syrian girl described abuse she experienced from her father inlaw: 'His [her husband] father tried to touch me as well. He displayed his genitals to me. He would start touching himself in front of me'. Sometimes, a girl's own parents or other family members contribute to abusive environments by forbidding them from complaining about their marriage. One married girl in Gaza stated: 'My mother asked me to stop complaining about my husband and to be patient because I have to worry about my younger sister's future and marriage chances' (FGD, older girls, Jabalia).

\section{Child Marriages That End in Divorce}

Girls who married early and are already divorced are particularly vulnerable. Overall, divorce is more common in Jordan (10\%) than in Gaza (5\%). However, in both samples, some girls who were married as children reported already being divorced, including $8 \%$ of the quantitative sample of ever-married Syrian girls living in Jordan.

Syrian refugees in Jordan, including ever-married girls and guardians of married girls, commented that divorce is relatively common in their communities. A father in Azraq camp (Jordan) observed, 'Some Syrians now get married and then get divorced a month or two later'. A Syrian refugee father of a 17-year-old divorced girl noted, 'When we came here in 2013-2014, the number of early marriage cases was very high. Then, the number of divorce cases had risen because they got married at a young age, so they got divorced'. A service provider noted how 'Divorce is a common outcome. The longest marriage lasts for 1 month, 1 month and a half, 2 months. I mean, for me, I have multiple cases that I know in this region. The whole thing fails. The life of divorced girls is miserable in many ways'.

Divorce often brings difficult consequences for girls who married as children, including restricted opportunities for their future. One young woman in Gaza said: 'I am divorced and I would like to return to school and complete my studies... but my family refused because I am divorced' (FGD, older adolescents, Jabalia). Among Syrian refugees in Jordan, divorced girls reported experiencing daily stigma and exclusion in their community, including being subject to 'dirty' language (18-yearold Syrian girl) and rejection by married women who assume that divorcees 'want 
to take away their husbands' (19-year-old Syrian girl). They also reported being excluded from services and programmes, which seldom mix unmarried and married girls because the latter's supposed greater sexual knowledge is perceived to threaten the 'purity' (freedom from immorality, especially of a sexual nature) of the former. Furthermore, some girls are forced by their in-laws to sign away their legal rights (including to children) before they are allowed to divorce. Jordanian law also stipulates that if the wife initiates the divorce, she must repay her dowry, which exacerbates the financial strain on girls' natal families (United Nations Development Programme, UNDP 2018).

\section{Impact of Child Marriage on Health and Wellbeing}

\section{Sexual and Reproductive Health}

Child marriage endangers adolescent girls' health due to early and frequent childbearing (WHO 2014). Among the married Gazan girls in our sample, $85 \%$ had ever been pregnant (median of 2 children). Less than one-third (32\%) reported ever using a family planning method-much less than adult women (over 50\%). Many (40\%) of the participants who had married as children had experienced complications during pregnancy, nearly double the rate for adult women (UNFPA 2016). Among married Syrian girls in the Jordan quantitative sample, $45 \%$ were either currently pregnant or had at least one living child; approximately one-third (33.5\%) already had one or more children.

Our qualitative research yields further insights into these girls' reproductive health. In Gaza, girls reported worries surrounding pregnancy and fertility, including if and when to have a child. As one 16-year-old girl in Shajaia explained, 'I worry about getting pregnant, I was okay in medical check-up, I am small and I feel my uterus isn't mature yet'. Mothers-in-law have a strong influence on decisions about fertility. One mother reportedly told her son to threaten his 16-year-old wife with divorce if she continued using contraceptives to avoid pregnancy (IDI, 16-yearold adolescent mother, Jabalia). Another married girl stated: 'If I have my period, my husband's family gets angry and says "that means she is not pregnant!" (FGD, older girls, Jabalia).

Married Syrian refugee girls in Jordan reported similar pressures around fertility from their husbands, families and communities. Although a few reported using contraception-which is free to all in Jordan regardless of nationality-most did not, often because of pressure to demonstrate their fertility and keep their husbands from taking another wife. A 17-year-old married Syrian girl explained: 'They told me he would marry another one if I couldn't become pregnant'. Another 16-year-old Syrian girl noted: 'I gave birth four months ago, I am not taking any contraceptives, no one in my family allows that'.

In Gaza, girls who married as children were dissatisfied with the quality of reproductive health services, with some reporting experiencing verbal or physical violence from medical staff during pregnancy or labour: 'Once an obese doctor stepped on my belly. I screamed, she swore bad words rudely' (FGD, older girls, Jabalia). 
Another girl from Shajaia said that the doctor slapped her when she was giving birth for the first time, saying 'Either you do as I tell you or I will kill you and your baby!' Box 1 illustrates the challenges faced by married girls seeking reproductive health services.

Box 1 Compound vulnerabilities: fear of reproductive health services

'I am broken'. That is how 17-year-old Hanna, from Khan Younis, describes her life
Married at the age of 14 to a man more than twice her age, she has already been pregnant four times and
has two children. Because her husband insists on 'many children, especially boys', against her wishes,
Hanna has been almost continuously pregnant since she was married
She found her first pregnancy terrifying: 'I was afraid when the baby was moving - because I had never
been told what to expect'. During delivery at the hospital, no one told her anything and 'the health
personnel... were not supportive'
After her son was born, two months premature, she was sent home immediately. Her son died. 'I never
forget him'. Hanna feels that both her body and soul have been broken. Her age, her continuous
pregnancies and her poor diet have combined to leave her badly anaemic and very weak. Hanna added,
'Early marriage is a disaster for a 14-year-old girl, it is suffocation'. She ended the interview by saying,
'No one should be terrified like I was'.

Among married Syrian girls in Jordan, our findings suggest that the lack of knowledge and support around SRH can endanger girls who married as children. Although quantitative data show that the vast majority of married girls reported having a source of information on puberty (87.7\%), less than half of married Syrian girls (45\%) could identify at least one form of contraception. However, social desirability bias may have reduced the accuracy of responses-especially given that the Jordan Population and Family Health Survey found that nearly all married girls (98.5\%) had heard of contraception (Department of Statistics and ICF 2019).

Even so, qualitative findings also suggest that lack of information is a challenge for married Syrian refugee girls. In Jordan, marriage and sexual activity are strongly linked, and discussing sexual topics is taboo (Al Omari et al. 2016). Several girls in the qualitative sample reported being shocked on their wedding night to discover what married life entails; some health professionals also noted that young brides do not understand how pregnancy happens. As one key informant in a host community explained, 'I worked with some children who were pregnant and they found that they're pregnant in their sixth month... because these children do not know that sexual relations make women pregnant'. There was a similar situation in Gaza: because of their limited experience, young age and lack of counselling services for married girls, pregnancy and delivery was reported to be a traumatic experience for many. A 15-year-old Syrian married girl described her experience: 'My pregnancy was very difficult, I was scared when the baby moved, I wasn't aware about what to do and what to avoid during that period. The delivery was complicated, as the placenta was low and I had bleeding and delivered through Caesarean section'.

Receipt of SRH services for girls married as children in Jordan is sometimes further restricted by legal barriers, as health providers currently report to the police any girls who are married under the legal age or those whose marriages are not officially registered (as part of Jordan's child marriage prevention efforts). A 15-year-old Syrian refugee girl shared her experience: 'I gave birth three months ago, the hospital 
called the police, and they immediately took custody of the baby - they did not allow me to breastfeed my daughter... she broke my heart'. Similarly, the mother-inlaw of a 14-year-old married girl reported her experience, explaining that 'I accompanied my daughter-in-law who was pregnant to the hospital, and when we arrived, staff immediately asked us about the marriage contract, and [when] I explained that there was no marriage contract, the staff said "she became pregnant by an illegal way... she doesn't have any proof'. Then, policemen came to us!!'.

\section{Nutrition and Hunger}

Findings from both samples suggest that girls married as children often struggle with hunger and lack of nutrition. Among girls who married as children in Gaza, $13 \%$ reported that early marriage had negatively affected their health and 53\% reported being unable to meet their basic needs, including food. Among Syrian refugees in Jordan, the mean score on the Food Insecurity Experience Scale (FIES) of the Food and Agriculture Organization of the United Nations (FAO) (which assesses people's access to adequate food) was 4.38 for households with married girls. This was similar to the overall score for all GAGE adolescents from all categories regardless of marital status (4.6) in Jordan, indicating that marriage does not appear to be associated with improved food security. Indeed, married adolescent girls were generally more vulnerable to food insecurity; $20 \%$ of married Syrian girls reported being hungry at least once in the past 4 weeks, compared to $17 \%$ among all GAGE participants.

As well as challenges around household food insecurity, many young girls in Gaza who married an extended family relative reported that their mothers-in-law use food as a way to control them (see Box 2). In Gaza, one 16-year-old mother from Shajaia was worried about food shortage, saying, 'We have spent some days with no food at home. I had to sell my jewellery to buy food'. Another Gazan girl explained, 'I cry sometimes when I am hungry and I don't have food. I try to sleep to forget food and my children do the same' (FGD, older girls, Jabalia).

Box 2 Food is used to control adolescent wives

\footnotetext{
Most married adolescent girls reported that their mothers-in-law control access to nutritious food and distribute food unfairly. A divorced girl from Shajaia said: 'When I was married, my motherin-law used to go outside the house and lock it so I was unable to get food. Also, at lunchtime, she was... distributing it [the food] as she likes. She never gave me or other daughters-in-law sufficient or good food. I convinced my husband for a while to bring me food. When she knew, she prevented that. Once she kept me three days without food'. Another girl from Jabalia (now separated from her husband) said: 'I talked to my mother-in-law when I was pregnant and feeling very sick as I didn't eat well. She told me to go to my parents' house and eat there! She mocked me and told me to go find another place to get good food!'
} 


\section{Conclusion and Implications}

Our findings underscore the complex and interconnecting factors that drive child marriage and highlight how it hinders girls from developing their full capabilities. Our analysis indicates that protracted conflict augments existing cultural and gender norms for child marriage, but does so in ways that vary across contexts-findings that align with the existing evidence reported in the MENA region (Presler-Marshall et al. 2020; Bukman 2018). Child marriage tends to increase in humanitarian contexts where it is seen as a way to maintain family honour, protect girls from violence, and secure their future (WAC 2014). Conflict also increases household poverty and triggers additional economic pressures that can put girls at greater risk of child marriage.

In both contexts, protracted conflict and displacement have exacerbated culturally rooted drivers of child marriage. As a traditional practice, child marriage is rooted in gender inequality; however, high levels of poverty and lack of opportunities for girls, especially in education, contribute to child marriage in Gaza. Among Syrian refugees in Jordan, the dual pressures of poverty and lack of physical and social protection linked to displacement are driving child marriage, resulting in higher rates of child marriage in these communities than were observed pre-crisis in Syria.

One important difference between Gaza and Jordan is that Palestinian girls and their families are less exposed to discrimination by the regulatory framework— such as entitlement to work and eligibility to receive social services-than Syrian refugees living in Jordan (Abu-Hamad et al. 2019). Cultural homogeneity and norms have also tended to act as a protective factor against violence, especially bullying and sexual harassment of girls and women in Gaza. In Jordan, however, Syrian refugees (especially girls) are exposed to high levels of discrimination, violence and bullying, including from within the host community (ibid.).

In Gaza, child marriage is slowly decreasing, but persists among some communities, driven mainly by cultural customs and beliefs. Despite this promising trend, our analysis suggests that some groups of adolescent girls who married as children may be overlooked by official records. Our qualitative data include adolescent girls who married as young as 12 years old; some only registered their marriages a few years after they actually got married, while others admitted falsifying documents to prove they were of the legal age. A more effective surveillance system should be developed to register and track all cases where girls marry as children.

Among Syrian refugees in Jordan, rates of child marriage are increasing (UNICEF 2018), driven mainly by poverty, displacement, violence, discrimination, and lack of educational and employment opportunities - all of which combine to reignite pre-existing cultural norms encouraging child marriage.

We conclude that even in conflict-affected settings, child marriage is contextspecific, which suggests that policy-makers need to understand the uniqueness of each context to design appropriate and effective interventions. Although parents in such settings often choose child marriage as a way to protect their daughters, preserve family honour and promote girls' wellbeing, our findings portray that in terms of consequences, it brings the opposite-a finding that aligns with other studies 
(Al-Modallal 2012; Higher Population Council 2017). Child marriage endangers girls' health, exposes them to violence and severely limits their future prospects (UNICEF 2018; Clark et al. 2017).

To end child marriage, there is a need for multi-sectoral strategic interventions to strengthen prevention, identification and support. National strategies should be developed to replace reactive, project-based, short-term initiatives around child marriage. To accelerate prevention efforts, community mobilisation for social norm change should involve men, families, religious institutions, and male and female youth. There are positive examples of community mobilisation in the region that could be scaled up, and which resulted in the establishment of multi-sectoral child protection networks, emergency protection shelters to protect women whose lives are in danger, and (more recently) change the legal age of marriage, both in Jordan and Palestine (UNFPA 2016; Abumaria 2019). Prevention efforts should also focus on empowering girls and increasing the educational opportunities open to them at secondary and university levels, targeting school dropouts for support through alternative education avenues. Other at-risk groups-including married girls, victims of gender-based violence and the poorest girls - should be targeted for protection and support.

Married girls are particularly vulnerable and need dedicated support-for example, health services should provide information, awareness sessions and be adolescent-friendly. Married girls' nutritional status should be closely monitored, with appropriate support where needed. There should be greater support for child brides exposed to violence, providing access to psychosocial services, counselling and legal aid. Divorced girls and survivors of gender-based violence should receive tailored support through protection networks and empowerment programmes.

Married young girls should be recognised as a 'left behind' category, entitling them to further protection and multi-sectoral support. The Palestinian and Jordanian governments have committed to eliminating child marriage by 2030, but to do so they must tackle these drivers to ensure that vulnerable adolescent girls are no longer left behind. Because norms have emerged as a strong driver for child marriage, more research is needed to better understand the dynamics related to norms and child marriage in humanitarian settings, and how these intersect with conflict and its consequences.

Acknowledgements We express our sincere gratitude to all the participants in this study in Jordan and Gaza for sharing their experiences and insights, and for giving their time so willingly. We would like to acknowledge the significant contributions of Dr Nicola Jones, the Director of the GAGE Programme towards leading the GAGE research design, implementation, data analysis and reporting and to Kate Pincock, Qualitative Researcher at GAGE program for her significant support and feedback. Special thanks to the data collection team in Gaza and Jordan especially the adolescent researchers' participants of the pilot study at Culture and Free Thoughts Association in Gaza, Research Team based at Mindset and the Information and Research Centre King Hussain Foundation in Jordan. Special thanks to Agnieszka Malachowska, MENA Manager at the GAGE programme and the team of transcribers and translators of the qualitative work.

\section{Declarations}

Conflict of interest The authors declare there are no conflict of interest to report. 
Open Access This article is licensed under a Creative Commons Attribution 4.0 International License, which permits use, sharing, adaptation, distribution and reproduction in any medium or format, as long as you give appropriate credit to the original author(s) and the source, provide a link to the Creative Commons licence, and indicate if changes were made. The images or other third party material in this article are included in the article's Creative Commons licence, unless indicated otherwise in a credit line to the material. If material is not included in the article's Creative Commons licence and your intended use is not permitted by statutory regulation or exceeds the permitted use, you will need to obtain permission directly from the copyright holder. To view a copy of this licence, visit http://creativecommons.org/licen ses/by/4.0/.

\section{References}

Abu-Hamad, B., N. Jones, E. Presler-Marshall, F. Samuels, and I. Gercama. 2019. Interrogating the Potential of a "Cash Plus" Approach to Tackle Multidimensional Vulnerability in Humanitarian Contexts: The Case of Syrian Refugees in Jordan. In Social Policy in the Middle East and North Africa: The New Social Protection Paradigm and Universal Coverage, ed. R. Jawad, N. Jones, and M. Messkoub, 178-197. Cheltenham: Edward Elgar Publishing.

Abumaria, D. 2019. Palestinian Authority Outlaws Child Marriage. Government of Mohammad Shtayyeh Raises the Minimum Age of Consent to 18. The Jerusalem Post, 15 November. https://www.jpost. com/middle-east/pa-outlaws-child-marriage-606874. Accessed on Jan 20, 2021.

Al Omari, O., N. Abdel Razeq, and M. Fooladi. 2016. Experience of Menarche Among Jordanian Adolescent Girls: An Interpretive Phenomenological Analysis. Journal of Paediatric and Adolescent Gynaecology 29: 246-251.

Al-Modallal, H. 2012. Patterns of Coping with Partner Violence: Experiences of Refugee Women in Jordan. Public Health Nursing 29 (5): 403-411.

Braun-Lewensohn, O., and K. Al-Sayed. 2018. Syrian Adolescent Refugees: How Do They Cope During Their Stay in Refugee Camps? Frontiers in Psychology 9: 1258.

Bukman, A. 2018. Causes and Consequences of Child Marriage Among Syrian Refugee Populations in Jordan: An Investigation of Perceptions. Amman: University of New Hampshire.

Clark, C., R. Spencer, I. Khalaf, L. Gilbert, N. El-Bassel, J. Silverman, and A. Raj. 2017. The Influence of Family Violence and Child Marriage on Unmet Need for Family Planning in Jordan. Journal of Family Planning and Reproductive Health Care 43 (2): 105-112.

Department of Statistics and ICF. 2019. Jordan Population and Family and Health Survey 2017-18. Amman and Rockville: Department of Statistics and ICF.

Elakkary, S., B. Franke, D. Shokri, S. Hartwig, M. Tsokos, and K. Püschel. 2014. Honour Crimes: Review and Proposed Definition. Forensic Science, Medicine, and Pathology 10: 76-82.

Elarab, R., and M. Sagbakken. 2019. Child Marriage of Female Syrian Refugees in Jordan and Lebanon: A Literature Review. Global Health Action 12 (1): 1585709.

GAGE Consortium. 2019. GAGE Conceptual Framework, 2nd ed. London: Gender and Adolescence: Global Evidence.

Gausman, J., A. Othman, A. Dababneh, M. Dabobe, I. Hamad, I. Daas, and A. Langer. 2020. A SocialEcological Examination into the Research, Policy and Health Service Delivery Environment Related to Early Marriage and Sexual and Gender-Based Violence Among Youth in Jordan. BMC International Health and Human Rights 20 (1): 1-19.

Higher Population Council (2017) A Study on Child Marriage in Jordan. Amman: Higher Population Council.

International Center for Research on Women, ICRW. 2016. Child Marriage Facts and Figures. www. icrw.org/child-marriage-facts-and-figures.

Jones, N., S. Baird, E. Presler-Marshall, A. Małachowska, K. Kilburn, B. Abu-Hamad, A. Essaid, W. Amaireh, J. Sajdi, K. Banioweda, T. Alabbadi, S. Alheiwidi, Q. Ashareef, S. Altal, W. Kharabsheh, H. Abu Taleb, M. Abu Azzam, and B. Abu Hammad. 2019. Adolescent Well-Being in Jordan: Exploring Gendered Capabilities, Contexts and Change Strategies. A Synthesis Report on GAGE Jordan Baseline Findings. London: Gender and Adolescence: Global Evidence. 
Karasapan, O., and S. Shah. 2019. Forced Displacement and Child Marriage: A Growing Challenge in MENA. Brookings Institution Blog, 19 June. https://www.brookings.edu/blog/future-development/ 2019/06/19/forced-displacement-and-child-marriage-a-growing-challenge-in-mena.

Ouis, P. 2009. Honourable Traditions? Honour Violence, Early Marriage and Sexual Abuse of Teenage Girls in Lebanon, the Occupied Palestinian Territories and Yemen. The International Journal of Children's Rights 17 (3): 445-474.

Palestinian Central Bureau of Statistics, PCBS. 2015. Palestinian Multiple Indicator Cluster Survey 2014. Final Report. Ramallah: PCBS.

PCBS. 2018. Preliminary Results of the Population, Housing and Establishments Census 2017. Ramallah: PCBS.

PCBS. 2019a. Palestinian Labour Force Survey: Annual Report. Ramallah: PCBS.

PCBS. 2019b. Preliminary Results of the Violence Survey in Palestinian Society 2019. Ramallah: PCBS.

PCBS. 2020. Palestinian Multiple Indicator Cluster Survey 2020. Final Report. Ramallah: PCBS.

Presler-Marshall, E., N. Jones, S. Alheiwidi, S. Youssef, B. Abu-Hamad, K. Bani Odeh, S. Baird, E. Oakley, S. Guglielmi, and A. Małachowska. 2020. Through Their Eyes: Exploring the Complex Drivers of Child Marriage in Humanitarian Contexts. London: Gender and Adolescence: Global Evidence.

Samuels, F., N. Jones, and B. Abu-Hamad. 2017. Psychosocial Support for Adolescent Girls in Postconflict Settings: Beyond a Health Systems Approach. Health Policy and Planning 32 (5): 40-51.

Sirdah, M. 2014. Consanguinity Profile in the Gaza Strip of Palestine: Large-Scale Community-Based Study. European Journal of Medical Genetics 57 (2): 90-94.

Tasker, R. 2018. Child Marriage Amongst Syrian Refugees: A Rational Response? Barcelona: Institute Barcelona Studies International (IBEI).

United Nations, UN. 2019. Identifying and Exploring the Nexus Between Human Trafficking, Terrorism, and Terrorism Financing. United Nations Security Council Counter-Terrorism Committee Executive Directorate (CTED). New York: CTED.

United Nations Children's Fund, UNICEF. 2014. A Study on Early Marriage in Jordan 2014. Amman: UNICEF Jordan.

UNICEF. 2018. Child Marriage: Latest Trends and Future Prospects. New York: UNICEF.

United Nations Development Programme (UNDP). 2018. Jordan Gender Justice: Assessment of Laws Affecting Gender Equality and Protection Against Gender-Based Violence. New York: UNDP.

United Nations High Commissioner for Refugees, UNHCR. 2019. Jordan. Fact sheet, July. UNHCR. https://relief-web.int/sites/reliefweb.int/files/resources/70665.pdf.

United Nations Human Rights Council. 2015. Resolution Adopted by the Human Rights Council 29/8, Strengthening Efforts to Prevent and Eliminate Child, Early and Forced Marriage, A/HRC/ RES/29/8. Geneva: Human Rights Council. www.right-docs.org/doc/a-hrc-res-29-8.

United Nations Population Fund, UNFPA. 2016. Palestine 2030. Demographic Change: Opportunities for Development. Palestine: UNFPA.

Women's Affairs Centre, WAC. 2014. Early Marriage in Gaza: Causes and Impact. Gaza: WAC.

Women's Refugee Commission (WRC). 2016. A Girl No More: The Changing Norms of Child Marriage in Conflict. New York: WRC.

World Bank. 2019. Data: Selected Countries and Economies. World Bank Group. https://data.worldbank. org/indicator/SP.ADO.TFRT?end=2017\&locations $=$ SY\&start $=2010$.

World Health Organization, WHO. 2014. Adolescent Pregnancy Fact Sheet. https://apps.who.int/iris/bitst ream/handle/10665/112320/WHO_RHR_14.08_eng.pdf;sequence=1

Publisher's Note Springer Nature remains neutral with regard to jurisdictional claims in published maps and institutional affiliations.

\section{Authors and Affiliations}

\section{Bassam Abu Hamad ${ }^{1}$. Samah Elamassie ${ }^{2}$. Erin Oakley ${ }^{3}$. Sarah Alheiwidi ${ }^{4}$ Sarah Baird ${ }^{5}$}

Samah Elamassie

dr.samah-taysier@hotmail.com 
Erin Oakley

emoakley@gwmail.gwu.edu

Sarah Alheiwidi

sarahalheiwidi97@outlook.com

Sarah Baird

sbaird@gwu.edu

1 Faculty of Public Health, Al-Quds University, 101, Tel El Hawa, Gaza, Palestine

2 UNRWA, Jabalia, Gaza, Palestine

3 Department of Environmental and Occupational Health, Milken Institute School of Public Health, The George Washington University, 950 New Hampshire Ave NW, Washington, DC 20052, USA

4 Gender and Adolescent: Global Evidence, AlDyaa Abu Nusair, Amman, Jordan

5 Department of Global Health, Milken Institute School of Public Health, The George Washington University, 950 New Hampshire Ave NW, Washington, DC 20052, USA 